\title{
Libman-Sacks Endocarditis Involving Tricuspid Valve in Systemic Lupus Erythematosus - A Case Report
}

\author{
Aishwarya Ghule ${ }^{1}$, Shilpa Abhay Gaidhane ${ }^{2}$, Sourya Acharya ${ }^{3}$, Charan Bagga ${ }^{4}$, Anil Wanjari ${ }^{5}$ \\ 1, 2, 3, 4, 5, Department of Medicine, Jawaharlal Nehru Medical College, Datta Meghe \\ Institute of Medical Sciences, Sawangi (M), Wardha, Maharashtra, India.
}

\section{INTRODUCTION}

Libman-Sacks endocarditis is non-infectious thrombotic involvement of cardiac valves seen in systemic lupus erythematosus.1,2 Mitral valve followed by aortic valve are involved in systemic lupus erythematosus. However, involvement of tricuspid valve is rare. ${ }^{3} \mathrm{~A}$ case of a 36 -year-old woman with systemic lupus erythematosus with isolated tricuspid valve endocarditis has been reported here. Within the background of the relevant medical literature, this is a rare event.

In systemic lupus erythematosus (SLE) patients, mostly the aortic and mitral valves are affected. ${ }^{4}$ Echo shows evidence of vegetation in tip and septa of tricuspid valve which is suggestive of Libman-Sacks endocarditis. In our case we have discussed Libman-Sacks endocarditis involving tricuspid valve.

\section{PRESENTATION OF CASE}

A 36-year-old woman was admitted to our emergency department with sudden onset of dyspnoea for the last two hours. Four years earlier, she had three miscarriages and thrombocytopenia; her rheumatologic profile was done in which antinuclear antibody (ANA) and anti-double stranded deoxy ribo-nuclease-antibodies levels were raised, complement $\mathrm{C} 3$ and $\mathrm{C} 4$ were low, C-reactive protein (CRP) was elevated, rheumatoid arthritis (RA) factor was negative, erythrocyte sedimentation rate (ESR) was elevated. Above all investigations were suggestive of systemic lupus erythematosus. Her therapy included prednisolone, hydroxyl-chloroquine, and methotrexate.

On examination, her pulse rate was 92 / minute, respiratory rate was 24 / minute, and oxygen saturation was $90 \%$. Her blood pressure was $100 / 70 \mathrm{~mm}$ of mercury. On chest auscultation, fine end-inspiratory crepitations were heard at the base of the lungs. On cardiac auscultation, tachycardia and short systolic murmur in the tricuspid area were found. Rest of the systemic examination was normal.

White blood counts were normal, C-reactive protein was elevated; antiphospholipid antibodies were raised. D-dimer and chest radiography were normal. Trans-thoracic 2 D echocardiography / Doppler study (Figure 1) showed normal left ventricular ejection fraction, mildly dilated right atrium and right ventricle, moderate to severe tricuspid regurgitation, mild pulmonary artery hypertension, no clot. It also showed vegetation on septal and anterior leaflet of tricuspid valve (tip and septa). All three-blood culture were negative suggestive of non-infective endocarditis. Computed tomography pulmonary angiography revealed no significant abnormalities and no evidence of pulmonary embolism. Hence, she was diagnosed as non-infective endocarditis in a SLE i.e., Libman-Sacks Endocarditis (LSE).
Corresponding Author: Dr. Shilpa A. Gaidhane, Professor, Department of Medicine, Jawaharlal Nehru Medical College, Datta Meghe Institute of Medical Sciences, Sawangi (M), Wardha, Maharashtra, India.

E-mail: drshilpagaidhane@gmail.com

DOI: $10.14260 / \mathrm{jemds} / 2021 / 251$

How to Cite This Article:

Ghule A, Gaidhane SA, Acharya S, et al. Libman-sacks endocarditis involving tricuspid valve in systemic lupus erythematosus - a case report. J Evolution Med Dent Sci 2021;10(16):1179-1181, DOI: 10.14260/jemds/2021/251

Submission 11-11-2020,

Peer Review 18-02-2021,

Acceptance 25-02-2021,

Published 19-04-2021.

Copyright (c) 2021 JEMDS. This is an open access article distributed under Creative Commons Attribution License [Attribution 4.0 International (CC BY 4.0)] 


\section{DISCUSSION OF MANAGEMENT}

Patient was a known case of SLE, hypothyroidism and she was on regular medication like tablet methotrexate, prednisolone and thyroxin respectively. On admission, we started with antibiotics like amoxicillin, methyl-prednisolone pulse therapy, diuretics, and warfarin. Patient improved with the treatment and was discharged on seventh day of admission on low dose steroids, diuretics and warfarin. Patient was followed for one year with three monthly 2-D Echo, international normalized ratio (INR) monitoring.

\begin{tabular}{|ccc|}
\hline Country & $\begin{array}{c}\text { Incidence } \\
\text { (Per 1 lakh / yr.) }\end{array}$ & $\begin{array}{c}\text { Prevalence } \\
\text { (Per 1 lakh / yr.) }\end{array}$ \\
US & 5.1 & 52.2 \\
UK & 3.8 & 26.2 \\
India & $0.9-3.1$ & $3.2-19.3$ \\
Japan & 2.9 & 28.4 \\
\hline Table 1. Global Epidemiology of Tricuspid Valve Endocarditis in SLE
\end{tabular}
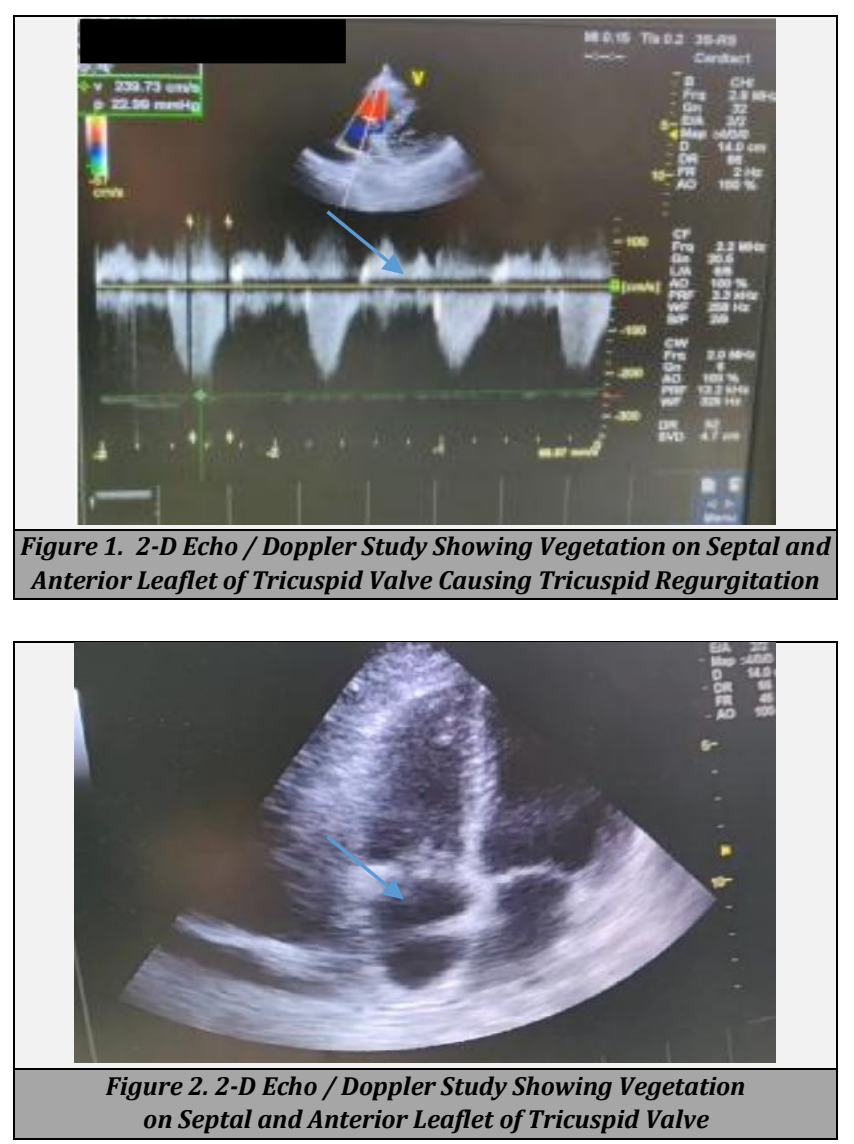

\section{DISCUSSION}

Libman-Sacks endocarditis involves tricuspid valves rarely. Surgical treatment is done more frequently when there are multiple valves involved, but it can be treated conservatively also. ${ }^{4}$

\section{Epidemiology}

Incidence and prevalence are increasing but also there is an improved survival and cases are milder. (Table 1)
- Geographical variability:

- African - American $>$ Caucasians (3 times more)

○ Asian - American and Hispanics > Caucasians

- $\quad$ Age at diagnosis:

$$
\begin{array}{ll}
\circ & 16-65 \text { years }-65 \% \text { of cases } \\
\circ & <16 \text { years }-20 \% \\
\circ & >65 \text { years }-15 \%
\end{array}
$$

\section{Pathogenesis}

In SLE, endothelial damage of the valvular surface occurs due to accumulation of antibodies including complement components, cytokinins tumour necrosis factor (TNF) alpha and interleukin six on the valve. This contributes to fibrosis of the cusp, thickening, scarring and ultimately distortion and dysfunction of the valve. Antiphospholipid antibodies accelerate the formation of thrombus in affected valves leading to fibrin platelet thrombi formation. Vegetation consists mainly of immune complexes, mononuclear cells fibrin and platelet thrombi. Turbulence of blood flow and jet symptoms are more prevalent in left-sided heart valves. Isolated tricuspid involvement as seen in our patient is very rare, and definite pathophysiology cannot be explained.

\section{Risk Factors}

Around $10 \%$ of SLE patients experience serious valvular endocarditis, as seen in prospective clinical and echocardiographic trials 3,5 They are associated with high level of antiphospholipid antibodies (APLA), higher severity of disease, longer disease duration, heart failure symptoms, progressive ventricular dysfunction. There is an association between APLA AND LS endocarditis. It has been reported by Vianna and colleagues that in Libman-Sacks endocarditis, valve lesions are extreme in secondary anti-phospho lipid syndrome than in patients with anti-phospholipid syndrome (APLS)

\section{Complications}

In SLE patients, valvular thickening and vegetation are frequently seen, but they induce mild regurgitation that can be treated with thrombolytic and anticoagulant treatment. It may get complicated to cause ischaemic strokes, peripheral embolisation, infective endocarditis and severe valvular regurgitation. If these occur, then surgery is indicated. ${ }^{3}$

\section{Diagnosis}

Diagnosis of LS endocardia are incidental, hence, require high degree of suspicion. It is often confused with bacterial endocarditis. 2-D Echo, negative blood culture, raised APL antibodies help in making diagnosis 5 .

\section{Treatment}

Conservative management (haemodynamically stable patient) of LSE include corticosteroid and anticoagulants. Corticosteroids decreases inflammation caused by SLE disease and hence, endocarditis 6 anticoagulation is required for 
prevention of thromboembolism from LSE. Surgery is more needed in secondary APLS and also patients are at a higher risk of complications like severe valvular regurgitation leading to uncontrolled heart failure, high risk of embolism ${ }^{7}$ Surgery is indicated after clinical decline or if there is disease progression. ${ }^{5}$ Literature describes surgical treatment of mitral valve LSE in the form of mitral valve repair and replacement. Surgery for tricuspid valve LSE involves vegetation removal, valve repair or bioprosthetic valve replacement. ${ }^{7}$

\section{CONCLUSIONS}

High degree of suspicion is required for making early diagnosis of LSE. Close clinical and echo cardiac monitoring is recommended for the patients managed with conservative treatment. Anticoagulation and control of SLE is the treatment of choice for these patients.

Financial or other competing interests: None.

Disclosure forms provided by the authors are available with the full text of this article at jemds.com.

\section{REFERENCES}

[1] Unic D, Planinc M, Baric D, et al. Isolated tricuspid valve libman-sacks endocarditis in systemic lupus erythematosus with secondary antiphospholipid syndrome. Tex Heart Inst J 2017;44(2):147-9.

[2] Bhimani AA, Hoit BD. Extensive nonbacterial thrombotic endocarditis isolated to the tricuspid valve in primary antiphospholipid syndrome. J Am Soc Echocardiogr 2010;23(1):107.e5-6.

[3] Laufer J, Frand M, Milo S. Valve replacement for severe tricuspid regurgitation caused by libman-sacks endocarditis. Br Heart J 1982;48(3):294-7.

[4] Moaref AR, Afifi S, Rezaian S, et al. Isolated tricuspid valve libman-sacks endocarditis and valvular stenosis: unusual manifestations of systemic lupus erythematosus. J Am Soc Echocardiogr 2010;23(3):341.e3-5.

[5] Perez-Villa F, Font J, Azqueta M, et al. Severe valvular regurgitation and anti-phospholipid antibodies in systemic lupus erythematosus: a prospective, long-term, follow-up study. Arthritis Rheum 2005;53(3):460-7.

[6] Dandekar UP, Watkin R, Chandra N, et al. Aortic valve replacement for libman-sacks endocarditis. Ann Thorac Surg 2009;88(2):669-71.

[7] Bai Z, Hou J, Ren W, et al. Diagnosis and surgical treatment for isolated tricuspid libman-sacks endocarditis: a rare case report and literatures review. J Cardiothorac Surg 2015;10:93. 